VOL. 195, NO. 4 THE AMERICAN NATURALIST APRIL 2020

Note

\title{
Maintenance of Fertility in the Face of Meiotic Drive
}

\author{
Lara Meade, ${ }^{1}$ Sam Ronan Finnegan, ${ }^{1}$ Ridhima Kad, ${ }^{1}$ Kevin Fowler, ${ }^{1}$ \\ and Andrew Pomiankowski ${ }^{1,2, *}$
}

1. Department of Genetics, Evolution, and Environment, University College London, Gower Street, London WC1E 6BT, United Kingdom; 2. CoMPLEX, University College London, Gower Street, London WC1E 6BT, United Kingdom

Submitted April 17, 2019; Accepted September 9, 2019; Electronically published March 9, 2020

Online enhancements: appendix, supplemental PDF. Dryad data: https://doi.org/10.5061/dryad.088kq34.

\begin{abstract}
AвSTRACT: Selfish genetic elements that gain a transmission advantage through the destruction of sperm have grave implications for drive male fertility. In the X-linked meiotic drive system (SR) of a stalk-eyed fly, we found that SR males have greatly enlarged testes and maintain high fertility despite the destruction of half of their sperm, even when challenged with fertilizing large numbers of females. Conversely, we observed reduced allocation of resources to the accessory glands that probably explains the lower mating frequency of SR males. Body size and eye span were also reduced, which are likely to impair viability and precopulatory success. We discuss the potential evolutionary causes of these differences between drive and standard males.
\end{abstract}

Keywords: accessory gland, meiotic drive, multiple mating, sex ratio distorter, sexual selection, sperm competition, stalk-eyed fly, testis.

\section{Introduction}

Meiotic drive genes gain a transmission advantage through manipulation of meiosis or gametogenesis and are likely to have profound ecological and evolutionary consequences, ranging from the evolution of sex determination systems and changes in karyotype, to impacts on population persistence and sexual selection (Hurst and Werren 2001; Jaenike 2001; Werren 2011; Lindholm et al. 2016). Drivers have been uncovered in a wide range of taxa, with a preponderance of linkage to the sex chromosomes in the heterogametic sex (Hurst and Pomiankowski 1991; Jaenike 2001; Taylor and Ingvarsson 2003). When meiotic drive occurs in males, it severely disrupts the maturation and fertilization capacity of noncarrier sperm, imposing a fer-

* Corresponding author; email: ucbhpom@ucl.ac.uk.

ORCIDs: Meade, https://orcid.org/0000-0002-5724-7413; Finnegan, https:// orcid.org/0000-0001-6893-7068; Fowler, https://orcid.org/0000-0001-9737-7549; Pomiankowski, https://orcid.org/0000-0002-5171-8755.

Am. Nat. 2020. Vol. 195, pp. 000-000. (C) 2020 by The University of Chicago. 0003-0147/2020/19504-59191\$15.00. All rights reserved.

DOI: $10.1086 / 707372$ tility disadvantage to organismal fitness (Price and Wedell 2008), which is exaggerated under conditions of sperm competition (Taylor et al. 1999; Angelard et al. 2008; Price et al. 2008a) and typically has pleiotropic viability costs in both sexes (Burt and Trivers 2006).

The extent to which these and other detrimental effects of sperm-killer drive promote adaptive responses in the host species has received limited attention. There is an extensive literature on genetic elements that interfere and suppress the action of drive. For example, in Drosophila species, suppressors of $\mathrm{X}$-linked drive have been found on the Y chromosome (Carvalho et al. 1997; Cazemajor et al. 1997; Branco et al. 2013) and throughout the rest of the genome (Carvalho and Klaczko 1993; Atlan et al. 2003; Tao et al. 2007). A more recent suggestion is that drive may promote the evolution of female polyandry in order to dilute the ejaculates of drive males (Haig and Bergstrom 1995; Zeh and Zeh 1997; Wedell 2013). There is some evidence for this from experimental evolution studies using populations exposed to meiotic drive in Drosophila pseudoobscura (Price et al. 2008b) and Mus musculus (Manser et al. 2017) and from natural populations in which the rate of multiple mating correlates negatively with the frequency of drive in D. pseudoobscura (Price et al. 2014) and Drosophila neotestacea (Pinzone and Dyer 2013). Female mate choice may additionally evolve in response to drive. In stalk-eyed flies, meiotic drive has been linked to small eye span, which may allow females to avoid mating with carrier males through assessing eye span (Wilkinson et al. 1998b; Cotton et al. 2014). Female house mice could avoid mating with drive males through detecting unique major histocompatibility alleles linked to the driving $t$ complex (Silver 1985; Lindholm et al. 2013), although evidence remains unclear (Lindholm and Price 2016).

Another as yet unexplored route by which males could adapt to drive is by increasing the allocation of resources to sperm production, in order to offset the destructive 
effect of drive on gametogenesis. Sperm number is positively correlated with testis size in many intraspecific studies (Gage 1994; Fry 2006; Hettyey and Roberts 2006), and increased testis size is a well-characterized evolutionary response to heightened sperm competition favoring greater sperm production (Hosken and Ward 2001; Pitnick et al. 2001; Simmons and García-González 2008; Gay et al. 2009). The loss of sperm in drive males could be compensated for by increased investment in testis size. Meiotic drive elements are typically found within inversions or other areas of low recombination that keep drive and insensitive responder loci together (Palopoli and Wu 1996; Johns et al. 2005; Dyer et al. 2007), facilitate the spread of modifiers that enhance transmission distortion (Hartl 1975; Larracuente and Presgraves 2012), and are predicted to be enriched for male-beneficial sexually antagonistic alleles (Rydzewski et al. 2016). For similar reasons, alleles that enable compensatory investment in testes could become associated with the drive haplotype.

We test this idea using the Malaysian stalk-eyed fly species Teleopsis dalmanni. This species harbors SR, an Xlinked driver that produces strongly female-biased broods as a result of the destruction of Y-bearing sperm (Presgraves et al. 1997; Wilkinson and Sanchez 2001). Meiotic drive arose around 2-3.5 million years ago in the Teleopsis clade, and the $\mathrm{X}^{\mathrm{SR}}$ drive chromosome in T. dalmanni is estimated to have diverged from a nondriving ancestor $\left(\mathrm{X}^{\mathrm{ST}}\right)$ around 1 million years ago (Swallow et al. 2005; Paczolt et al. 2017) and is characterized by a large inversion(s) covering most of the X chromosome (Johns et al. 2005; Paczolt et al. 2017). $X^{\text {SR }}$ is found at appreciable frequencies (10\%-30\%) across populations and generations (Wilkinson et al. 2003; Cotton et al. 2014) but appears to lack genetic suppressors (Reinhold et al. 1999; Wolfenbarger and Wilkinson 2001; Paczolt et al. 2017). This means that there has been ample time and opportunity for adaptive responses to evolve in male carriers of the drive chromosome.

We determined whether SR and ST (standard) males (males carrying $\mathrm{X}^{\mathrm{SR}}$ and $\mathrm{X}^{\mathrm{ST}}$, respectively) differed in their reproductive (testis and accessory gland size) and morphological (eye span and body size) traits. Testis size predicts the amount of sperm found within female storage (Fry 2006). Accessory glands produce all nonsperm components of the ejaculate, and accessory gland size is positively associated with male mating frequency (Baker et al. 2003; Rogers et al. 2005a, 2005b). Body size and eye span are also important predictors of male mating frequency (Wilkinson et al. 1998a; Small et al. 2009; Cotton et al. 2010). We determined SR and ST male sperm production by mating them to low or high numbers of females over a 10 -h period and counting the number of fertilized eggs produced. Males were also exposed to females over a short time period $(30 \mathrm{~min})$ to compare the copulation rate of SR and ST males.

\author{
Material and Methods \\ Experimental Animals
}

Details of stock collection and day-to-day upkeep can be found in the appendix (available online). Experimental males were taken from the SR stock population, in which males are a $\sim 50: 50$ mix of $X^{\mathrm{SR}}$ and $\mathrm{X}^{\mathrm{ST}}$ genotypes. Experimental females were taken from the ST stock population, which lacks meiotic drive. Single nonvirgin males were allowed to mate freely with either one or five virgin ST stock females over a period of $10 \mathrm{~h}$. Mated females were allowed to lay eggs for 14 days, by which time most females had stopped laying fertile eggs. Fecundity was recorded through egg counts, and egg hatch was used as an estimate for fertility. On the following day, experimental males and a similar number of unmated males were anesthetized on ice, and their testes and accessory glands were removed (fig. 1A) and photographed under differential interference contrast microscopy. Organ area was measured at $\times 50$ magnification by tracing the outline. Male eye span (Hingle et al. 2001) and a proxy for body size, thorax length (Rogers et al. 2008), were measured.

In a second experiment, SR stock males were introduced to two ST stock nonvirgin females at artificial dawn. All copulations were counted during $30 \mathrm{~min}$. To minimize any effects on mating frequency due to female choice, the experimental males were standardized to have a narrow range of eye span $(7.5-8.5 \mathrm{~mm})$.

Males from both experiments were genotyped using either two X-linked insertion-deletion markers, comp162710 and $c n v 395$, or a microsatellite marker, $m s 395$. Allele size of these markers reliably indicates the SR genotype of the males in our laboratory stocks (Meade et al. 2018).

\section{Statistical Analysis}

We tested whether male genotypes differed in their morphological (body size and eye span; linear models) and reproductive (testis size and accessory gland size; linear mixed effects models) traits. Differences in relative trait size between genotypes, as well as in absolute trait size (models where body size is excluded), are reported. The total number of fertile eggs (Poisson generalized linear mixed effects model [GLMM]) and proportion fertility (fertile eggs, nonfertile eggs; binomial GLMM) of females are compared when mated to SR (i.e., $\mathrm{X}^{\mathrm{SR}} / \mathrm{Y}$ genotype) or ST (i.e., $\mathrm{X}^{\mathrm{ST}} / \mathrm{Y}$ genotype) males. We also tested whether male reproductive traits and their interaction with male genotype were important predictors of fertility. Last, we tested whether SR and ST males differed in their mating frequency over $30 \mathrm{~min}$ by comparing the likelihood that SR and ST males mate at all (binomial GLMM), as well as 

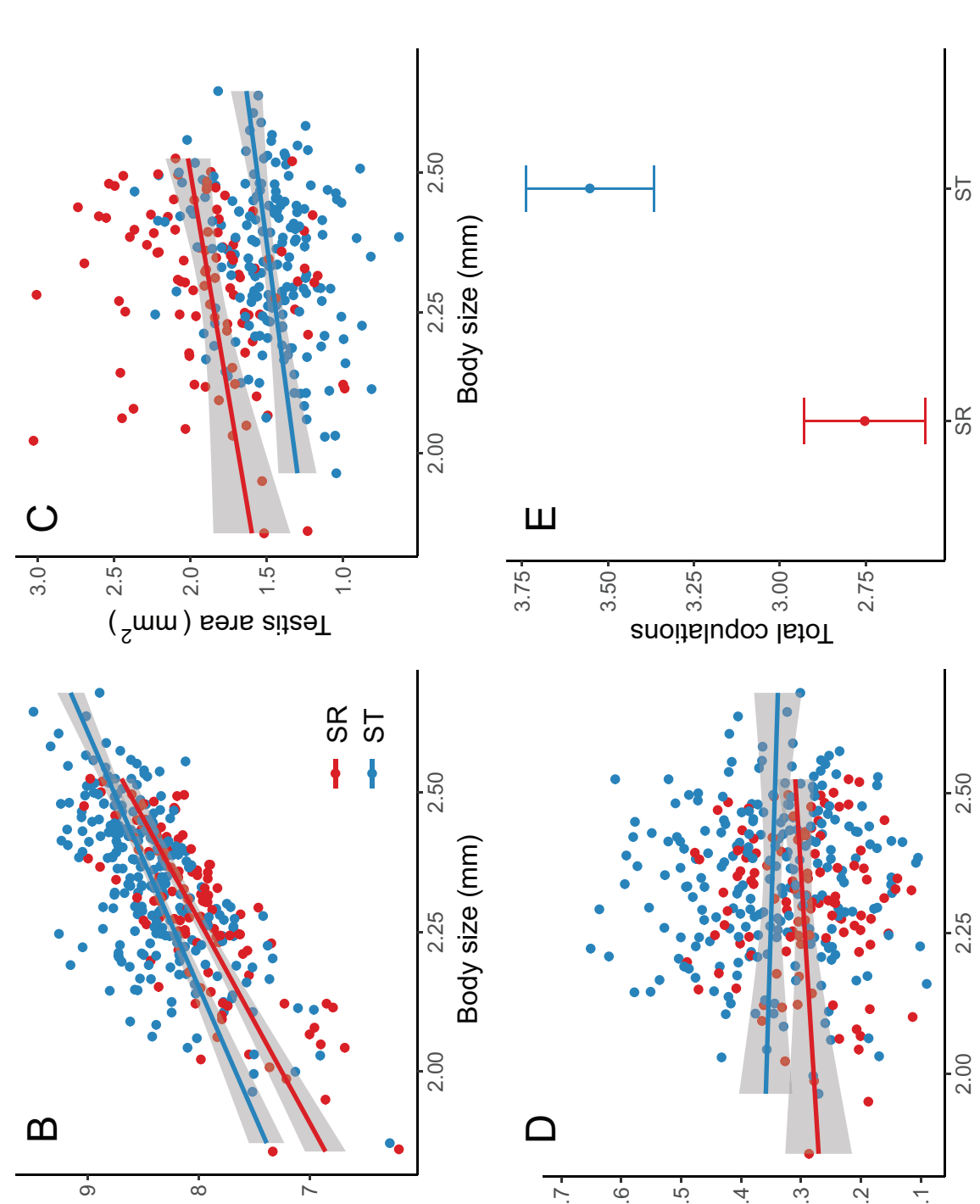

(mu) uedsəКヨ
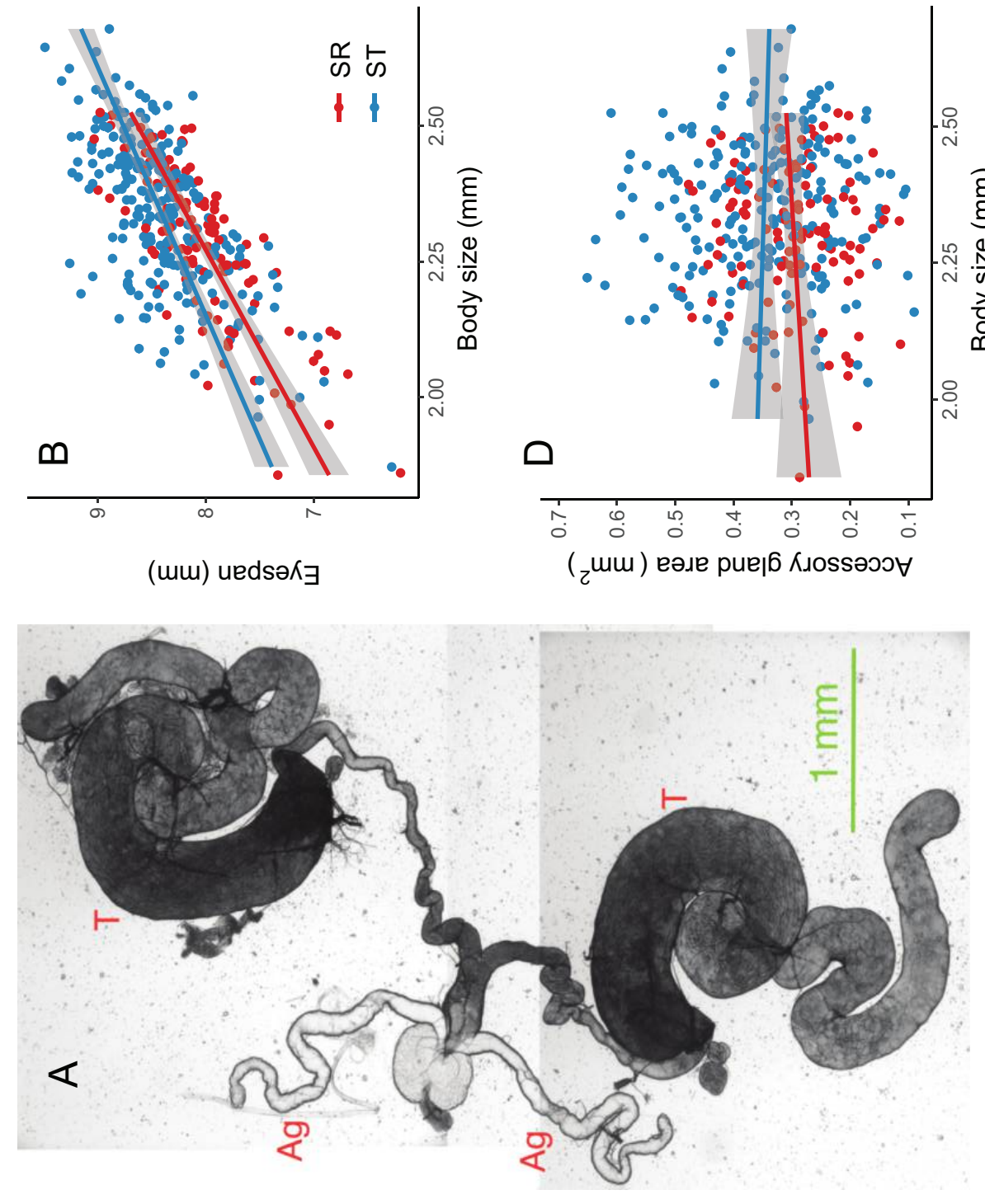

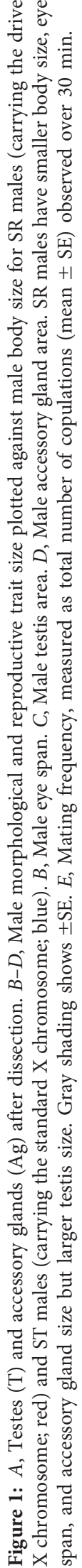

This content downloaded from 128.041.035.054 on March 10, 2020 08:29:29 AM 
the total number of copulations among males that mated at least once (Poisson GLMM).

To avoid collinearity of male morphological and reproductive traits with body size, models used residual values (Dormann et al. 2013). Where appropriate, experimental batch was included as a random effect. Further details and model effect sizes can be found in the appendix.

\section{Results}

\section{SR Trait Size}

SR males had small body size (mean \pm SE, $2.290 \pm$ $0.013 \mathrm{~mm})$ compared to ST males $(2.336 \pm 0.009 \mathrm{~mm}$; $F_{1,357}=8.745, P=.003$; fig. $\left.1 B\right)$. SR males also had small absolute eye span (SR: $8.048 \pm 0.046 \mathrm{~mm}$; ST: $8.402 \pm$ $0.031 \mathrm{~mm} ; F_{1,357}=42.631, P<.001$; fig. $\left.1 B\right)$ and relative eye $\operatorname{span}\left(F_{1,355}=0.713, P=.016\right)$, especially when body size was small (body size $\times$ genotype interaction: $F_{1,355}=$ 4.175, $P=.042)$.

Despite the small body size of SR males, the testis size of SR males was large $\left(1.940 \pm 0.050 \mathrm{~mm}^{2}\right)$ compared to that of ST males $\left(1.54 \pm 0.028 \mathrm{~mm}^{2} ; F_{1,280.16}=73.796\right.$, $P<.001$; fig. $1 C)$. SR males also had large relative testis size $\left(F_{1,282.78}=99.982, P<.001\right)$. In contrast, $\mathrm{SR}$ males had small absolute accessory gland size (SR: $0.306 \pm$ $0.011 \mathrm{~mm}^{2}$; ST: $0.348 \pm 0.010 \mathrm{~mm}^{2} ; F_{1,335.36}=16.353$, $P<.001$; fig. $1 D)$ and relative accessory gland size $\left(F_{1,334.03}=7.801, P=.006\right)$. Taking relative values for each genotype, eye span $\left(F_{1,286}=19.892, P<.001\right)$ and accessory gland size $\left(F_{1,274.418}=26.008, P<.001\right)$ increased with testis size, but the rate was reduced in SR males (interaction eye span: $F_{1,286}=5.261, P=.023$; fig. A1; interaction accessory glands: $F_{1,268}=8.375, P=$ .004 , fig. A2; figs. A1, A2 are available online).

\section{SR Fertility}

SR males did not differ from ST males in total (mean \pm SE, SR: $112.047 \pm 8.290 ;$ ST: $107.053 \pm 5.597 ; \chi_{1}^{2}=$ 2.416, $P=.120, N=215$; fig. $2 A, 2 B$ ) or proportion fertility (SR: $0.833 \pm 0.025$; ST: $0.762 \pm 0.019 ; \chi_{1}^{2}=2.469$, $P=.116, N=215)$ when kept with females over an extended $10-\mathrm{h}$ period. Males mating with five females achieved higher total fertility (one female: 79.231 \pm 5.090; five females: $138.123 \pm 6.653 ; \chi_{1}^{2}=43.698, P<$ $.001, N=215$ ) but a lower proportion fertility (one female: $0.804 \pm 0.024$; five females: $0.763 \pm 0.199 ; \chi_{1}^{2}=$ $6.021, P=.014, N=215$ ) than those mating with a single female. The interaction between mating group (one or five females) and genotype did not influence total fertility $\left(\chi_{1}^{2}=0.591, P=.442, N=215\right)$ or proportion fertility $\left(\chi_{1}^{2}=1.377, P=.241, N=215\right)$.
Male testis size was an important predictor of fertility. Both total fertility $\left(\chi_{1}^{2}=5.897, P=.015, N=165\right.$; fig. $2 C$, $2 D)$ and proportion fertility $\left(\chi_{1}^{2}=18.837, P<.001, N=\right.$ $165)$ were greater among males with larger testis size, even when accounting for male body size (total: $\chi_{1}^{2}=6.216$, $P=.013, N=165$; proportion: $\chi_{1}^{2}=16.646, P<.001$, $N=165)$. The addition of testis size did not alter the relationship between genotype and total fertility $\left(\chi_{1}^{2}=0.018\right.$, $P=.895, N=173)$ or proportion fertility $\left(\chi_{1}^{2}=0.260\right.$, $P=.610, N=173)$. There was no interaction between testis size and genotype predicting total $\left(\chi_{1}^{2}=0.164, P=\right.$ .686, $N=173)$ or proportion fertility $\left(\chi_{1}^{2}=0.617, P=\right.$ $.432, N=173)$. Accessory gland size did not predict total fertility $\left(\chi_{1}^{2}=0.032, P=.858, N=165\right)$ or proportion fertility $\left(\chi_{1}^{2}=0.160, P=.689, N=165\right)$.

\section{SR Mating Frequency}

A total of 493 copulations from 193 males were observed over the 30 -min mating trials. SR males (mean \pm SE, $2.750 \pm 0.175, N=81)$ copulated fewer times on average than ST males $\left(3.550 \pm 0.186, N=76 ; \chi_{1}^{2}=6.304, P=\right.$ .012 ; fig. $1 E$ ) but were not less likely to mate at least once (SR: $81 / 104$; ST: $76 / 89 ; \chi_{1}^{2}=1.665, P=.197, N=193$ ).

\section{Discussion}

One of the main features of meiotic drive in males is reduced sperm production due to the dysfunction of noncarrier sperm. This has been reported to cause a loss in fertility in a variety of species, including Drosophila (Hartl et al. 1967; Jaenike 1996; Angelard et al. 2008; Price et al. 2012; Pinzone and Dyer 2013), house mice (Carroll et al. 2004), and Silene alba (Taylor et al. 1999). Here we present evidence that SR males in Teleopsis dalmanni overcome this deficit by having greatly enlarged testes. SR males carry an extreme form of the $\mathrm{X}^{\mathrm{SR}}$ drive chromosome, siring femaleonly broods as a result of the dysfunction of Y-bearing gametes. Despite gamete loss, SR males achieve fertility at a level equivalent to that of ST males when exposed to either a single female or five females over a 10 -h period (fig. 2). Our results contradict a previous study that found an SR fertility deficit using a similar design (Wilkinson et al. 2006). But this study measured fertility as the number of adults that eclosed, compounding fertility with egg-to-adult survival. Recent work shows that larval survival is reduced in drive heterozygous females (Finnegan et al. 2019), which could account for the apparent drop in SR male fertility. The patterns in T. dalmanni are in contrast to other insect species with X-linked meiotic drive, which generally show a deficiency in fertility of drive males after either a single or multiple matings (Jaenike 1996; Atlan et al. 2004; Angelard et al. 2008; Price et al. 2012; Pinzone and Dyer 2013). 
A
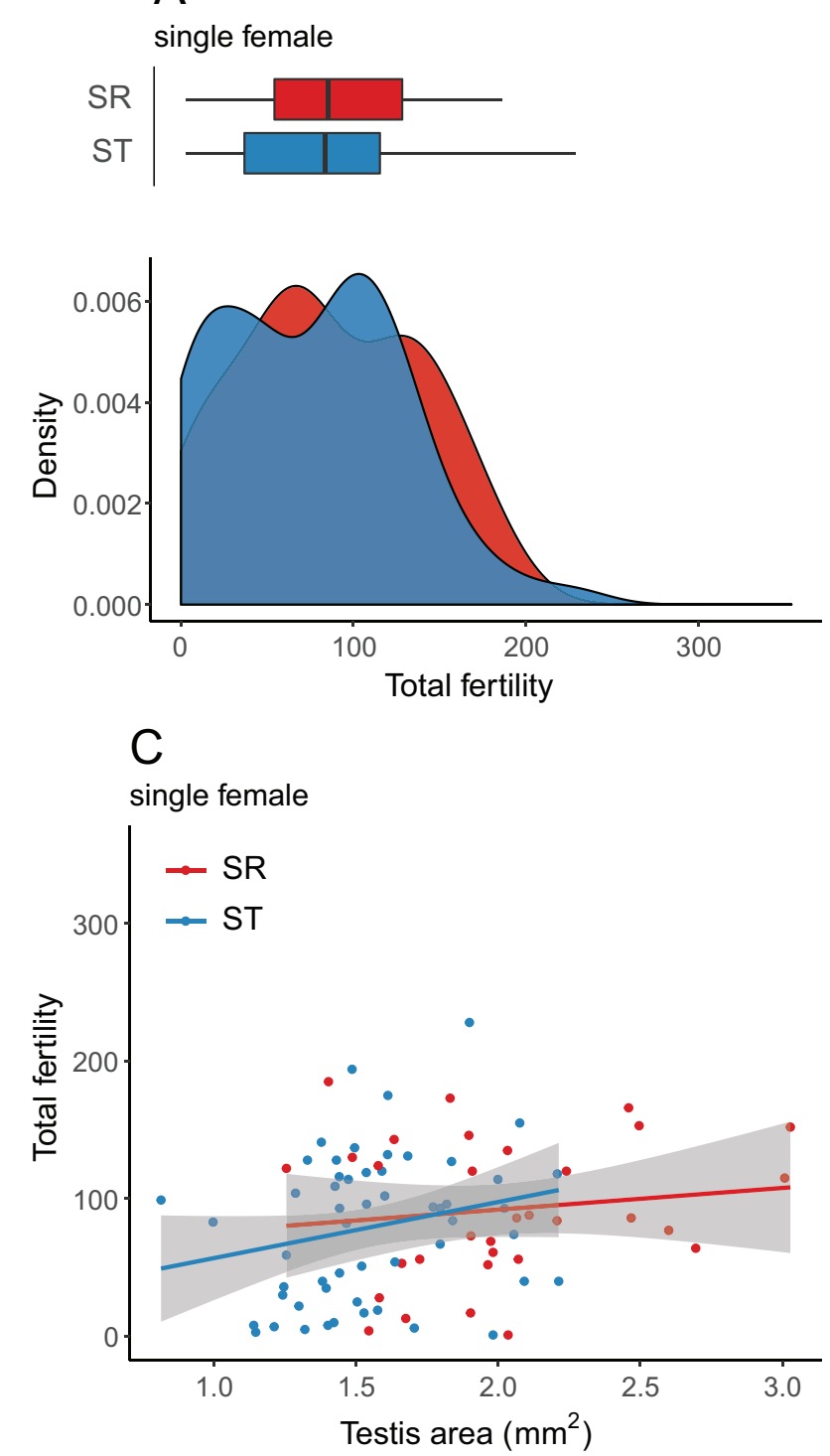

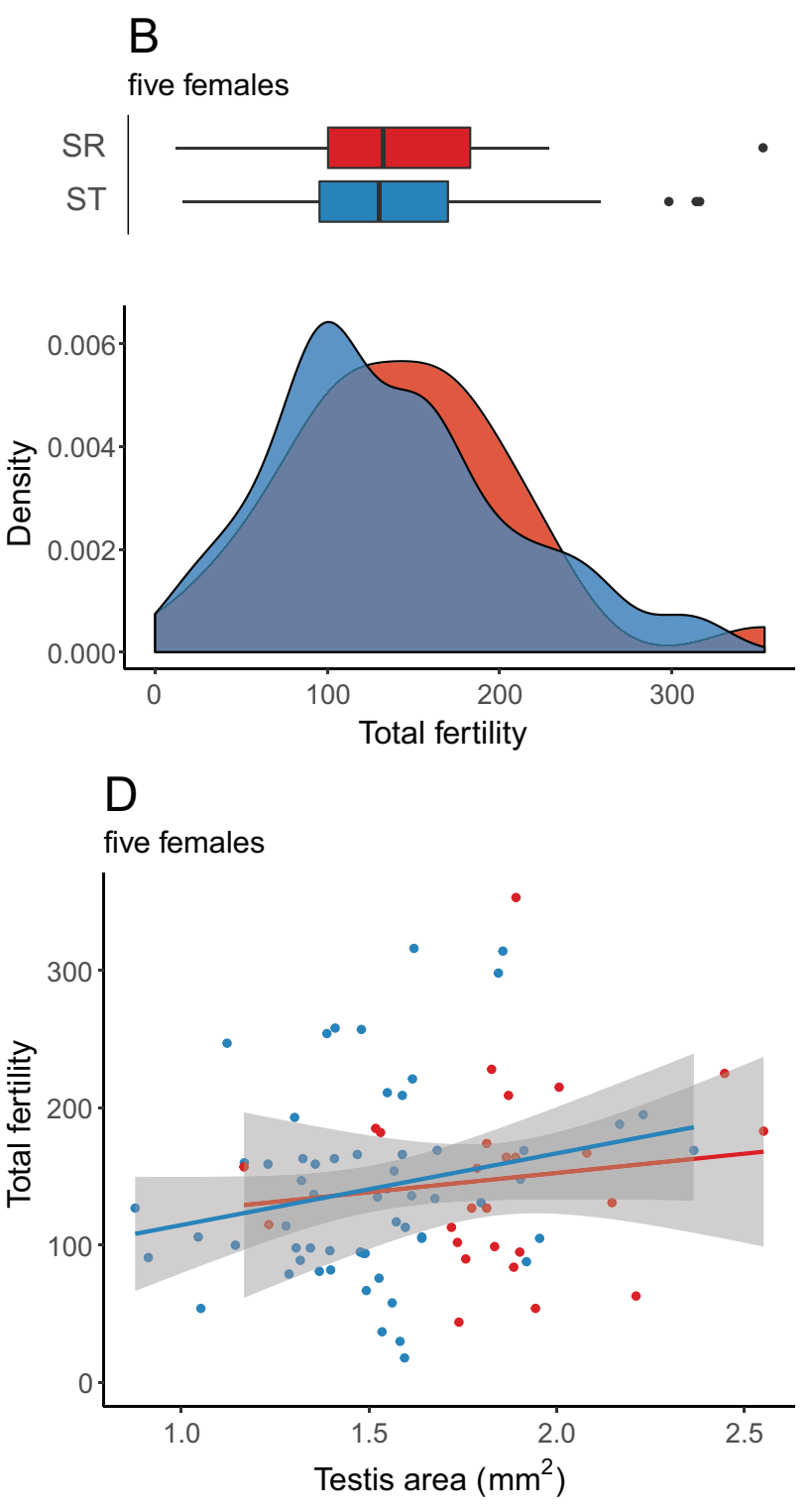

Figure 2: $A, B$, Boxplots (median and interquartile range; top) and Kernel probability density of measures (bottom) of total fertility of SR males (carrying the drive X chromosome; red) and ST males (carrying the standard X chromosome; blue). A, Mated to a single female. $B$, Mated to five females. Across both mating regimes, SR and ST males did not differ in the number of eggs fertilized. $C, D$, Absolute testis area plotted against total fertility. $C$, Mated to a single female. $D$, Mated to five females. Across both mating regimes, total fertility increased with testis area in SR and ST males. Gray shading shows \pm SE.

These experiments were designed to test whether daily sperm reserves differ between SR and ST males, not to replicate normal levels of mating observed under natural conditions, which occur at far lower rates (Cotton et al. 2015). On dissection, we discovered that SR males have greatly enlarged testes (fig. 1C), about $26 \%$ larger than those of ST males. This difference remained after controlling for body size (fig. 1C). Our interpretation is that the increase in testis size allowed SR males to compensate for the loss of sperm due to the action of meiotic drive. This is supported by the finding that fertility increased with increasing testis size, for both absolute and relative testis size, in both SR and ST males (fig. 2). Our interpretation also aligns with previous findings that SR male ejaculates deliver similar numbers of sperm as do those of ST males after single and multiple matings (Meade et al. 2018). Despite the destruction of half of the sperm of SR males, the increased investment in their testis size (i.e., sperm production) allows them to deliver sufficient sperm to achieve a fertility similar to that of ST males. To further understand 
the extent of this compensation, we need to assess SR male success under sperm competition, which is the norm in T. dalmanni (Wilkinson et al. 1998a; Baker et al. 2001; Corley et al. 2006). Previous work suggests that SR males perform poorly under sperm competition (Wilkinson et al. 2006), but this assessment again does not take account of the lower egg-to-adult viability of $\mathrm{X}^{\mathrm{SR}}$ carriers (Finnegan et al. 2019), which could simulate an advantage of ST males in sperm competition. In our experimental design, autosomal background was standardized across SR and ST males. So it seems likely that control of testis size is linked to alleles that are located in the $\mathrm{X}^{\mathrm{SR}}$ chromosomal inversion and that such alleles arose as an adaptive response to sperm dysfunction caused by drive, but further investigation is needed to establish this view.

We found morphological trait divergence in accessory gland size, which is small in SR males, even after controlling for body size (fig. 1D). Previous work in T. dalmanni shows that accessory gland size is linked with the mating rate (Baker et al. 2003; Rogers et al. 2005a). This might explain why the mating frequency of SR males was low, being about $75 \%$ of the rate for ST males over a 30 -min period (fig. $1 E$ ). In addition, SR males have small body size and small eye span for their body size (fig. 1), traits likely to reduce male mating success both in male-male agonistic interactions (Panhuis and Wilkinson 1999; Small et al. 2009) and in attracting and mating with females (Wilkinson and Reillo 1994; Hingle et al. 2001; Cotton et al. 2010). The increased allocation of resources to testes in SR males potentially causes a reduction in the resources available for investment in accessory glands, as both traits develop over several weeks after eclosion (Baker et al. 2003; Rogers et al. 2008). Resource competition with testes is not an obvious reason for reduced body size and eye span, which are determined during larval development. However, expression of these traits might be connected via juvenile hormone, which has been shown to mediate a trade-off between eye span and testes in stalk-eyed flies (Fry 2006).

Small body size and eye span are also likely to arise from the low genetic condition of drive males. The $T$. dalmanni SR inversion(s) covers nearly all of the X chromosome, capturing one-third of the stalk-eyed fly genome (Johns et al. 2005; Paczolt et al. 2017). $\mathrm{X}^{\mathrm{SR}}$ alleles will be subject to weak natural selection as a result of reduced recombination and will be liable to accumulate deleterious mutational effects (Kirkpatrick 2010). Consistent with a lack of recombination, there are 955 fixed sequence differences between transcripts linked to $\mathrm{X}^{\mathrm{SR}}$ and $\mathrm{X}^{\mathrm{ST}}$ (Reinhardt et al. 2014). Such mutations are expected to have a negative effect on costly, condition-dependent traits, such as body size and eye span, whose expression is affected by multiple loci distributed throughout the genome (David et al. 2000; Cotton et al. 2004; Bellamy et al.
2013). Given that SR males have small eye span, they will be unattractive and will gain fewer mating opportunities. Consequently, investment in accessory glands that enable higher mating rates will give lower returns than the diversion of resources into larger testes that allow SR males to produce ejaculates of a size equivalent to those of ST males and that allow SR males to be able to compete under the conditions of high sperm competition seen in stalk-eyed flies. These ideas about linking resource allocation, condition, and mating rates need further investigation, in particular under the mating conditions that occur in the wild.

Here we demonstrate for the first time that through investment in testis size, drive males can maintain fertility, despite sperm destruction. Other responses to drive, such as genetic suppression, polyandry, and female choice, reduce the transmission advantage gained by drive and lead to reductions in the equilibrium frequency of drive (Hartl 1975; Taylor and Jaenike 2002; Holman et al. 2015). In sharp contrast, increased investment in sperm production intensifies the transmission of drive, because the fertility gain to the individual male is also beneficial to the drive element itself. Such an association with meiotic drive has been neither theoretically modeled nor empirically studied previously, but it has implications for the spread and equilibrium frequency of drive in natural populations.

\section{Acknowledgments}

We thank Jerry Wilkinson and two anonymous reviewers and editors Stephen Chenoweth and Alice Winn for their insight and encouragement. Funding was provided by a Natural Environment Research Council (NERC) Studentship held by L.M., by Engineering and Physical Sciences Research Council awards (EP/F500351/1, EP/I017909/ 1) to A.P., and by NERC grants (NE/G00563X/1, NE/ R010579/1) to K.F. and A.P. No ethical approval was required for this research.

Statement of authorship: All authors contributed to conceiving the project and methodology; L.M. and R.K. collected data on fertility and morphology; S.F. collected data on mating frequency; L.M. analyzed the data; L.M. and A.P. led the writing of the manuscript with input from K.F.

\section{Data and Code Availability}

Data have been uploaded to the Dryad Digital Repository (Meade et al. 2020, https://doi.org/10.5061/dryad.088kq34).

\section{Literature Cited}

Angelard, C., C. Montchamp-Moreau, and D. Joly. 2008. Femaledriven mechanisms, ejaculate size and quality contribute to the lower fertility of sex-ratio distorter males in Drosophila simulans. BMC Evolutionary Biology 8:326. 
Atlan, A., C. Capillon, N. Derome, D. Couvet, and C. MontchampMoreau. 2003. The evolution of autosomal suppressors of sexratio drive in Drosophila simulans. Genetica 117:47-58.

Atlan, A., D. Joly, C. Capillon, and C. Montchamp-Moreau. 2004. Sex-ratio distorter of Drosophila simulans reduces male productivity and sperm competition ability. Iournal of Evolutionary Biology 17:744-751.

Baker, R. H., R. Ashwell, T. Richards, K. Fowler, T. Chapman, and A. Pomiankowski. 2001. Effects of multiple mating and male eye span on female reproductive output in the stalk-eyed fly, Cyrtodiopsis dalmanni. Behavioral Ecology 12:732-739.

Baker, R. H., M. Denniff, P. Futerman, K. Fowler, A. Pomiankowski, and T. Chapman. 2003. Accessory gland size influences time to sexual maturity and mating frequency in the stalk-eyed fly, Cyrtodiopsis dalmanni. Behavioral Ecology 14:607-611.

Bellamy, L., N. Chapman, K. Fowler, and A. Pomiankowski. 2013. Sexual traits are sensitive to genetic stress and predict extinction risk in the stalk-eyed fly, Diasemopsis meigenii. Evolution 67:26622673

Branco, A. T., Y. Tao, D. L. Hartl, and B. Lemos. 2013. Natural variation of the $\mathrm{Y}$ chromosome suppresses sex ratio distortion and modulates testis-specific gene expression in Drosophila simulans. Heredity 111:8-15.

Burt, A., and R. Trivers. 2006. Genes in conflict: the biology of selfish genetic elements. Harvard University Press, Cambridge, MA

Carroll, L. S., S. Meagher, L. Morrison, D. J. Penn, and W. K. Potts. 2004. Fitness effects of a selfish gene (the Mus $t$ complex) are revealed in an ecological context. Evolution 58:1318-1328.

Carvalho, A. B., and L. B. Klaczko. 1993. Autosomal suppressors of sex-ratio in Drosophila mediopunctata. Heredity 71:546-551.

Carvalho, A. B., S. C. Vaz, and L. B. Klaczko. 1997. Polymorphism for Y-linked suppressors of sex-ratio in two natural populations of Drosophila mediopunctata. Genetics 146:891-902.

Cazemajor, M., C. Landré, and C. Montchamp-Moreau. 1997. The sex-ratio trait in Drosophila simulans: genetic analysis of distortion and suppression. Genetics 147:635-642.

Corley, L. S., S. Cotton, E. McConnell, T. Chapman, K. Fowler, and A. Pomiankowski. 2006. Highly variable sperm precedence in the stalk-eyed fly, Teleopsis dalmanni. BMC Evolutionary Biology 6:53.

Cotton, A. J., S. Cotton, J. Small, and A. Pomiankowski. 2015. Male mate preference for female eyespan and fecundity in the stalkeyed fly, Teleopsis dalmanni. Behavioral Ecology 26:376-385.

Cotton, A. J., M. Földvári, S. Cotton, and A. Pomiankowski. 2014. Male eyespan size is associated with meiotic drive in wild stalkeyed flies (Teleopsis dalmanni). Heredity 112:363-369.

Cotton, S., K. Fowler, and A. Pomiankowski. 2004. Condition dependence of sexual ornament size and variation in the stalkeyed fly Cyrtodiopsis dalmanni (Diptera: Diopsidae). Evolution 58:1038-1046.

Cotton, S., J. Small, R. Hashim, and A. Pomiankowski. 2010. Eyespan reflects reproductive quality in wild stalk-eyed flies. Evolutionary Ecology 24:83-95.

David, P., T. Bjorksten, K. Fowler, and A. Pomiankowski. 2000. Condition-dependent signalling of genetic variation in stalk-eyed flies. Nature 406:186-188.

Dormann, C. F., J. Elith, S. Bacher, C. Buchmann, G. Carl, G. Carré, J. R. G. Marquéz, et al. 2013. Collinearity: a review of methods to deal with it and a simulation study evaluating their performance. Ecography 36:27-46.
Dyer, K. A., B. Charlesworth, and J. Jaenike. 2007. Chromosomewide linkage disequilibrium as a consequence of meiotic drive. Proceedings of the National Academv of Sciences of the USA 104:1587-1592.

Finnegan, S. R., N. J. White, D. Koh, M. F. Camus, K. Fowler, and A. Pomiankowski. 2019. Meiotic drive reduces egg-to-adult viability in stalk-eyed flies. Proceedings of the Roval Societv B 286:20191414.

Fry, C. L. 2006. Juvenile hormone mediates a trade-off between primary and secondary sexual traits in stalk-eyed flies. Evolution and Development 8:191-201.

Gage, M. J. G. 1994. Associations between body size, mating pattern, testis size and sperm lengths across butterflies. Proceedings of the Roval Society B 258:247-254.

Gay, L., D. J. Hosken, R. Vasudev, T. Tregenza, and P. E. Eady. 2009. Sperm competition and maternal effects differentially influence testis and sperm size in Callosobruchus maculatus. Journal of Evolutionarv Biology 22:1143-1150.

Haig, D., and C. T. Bergstrom. 1995. Multiple mating, sperm competition and meiotic drive. Lournal of Evolutionary Biology 8: 265-282.

Harrison, X. A. 2014. Using observation-level random effects to model overdispersion in count data in ecology and evolution. Peer] 2:e616.

Hartl, D. L. 1975. Modifier theory and meiotic drive. Theoretical Population Biology 7:168-174.

Hartl, D. L., Y. Hiraizumi, and J. Crow. 1967. Evidence for sperm dysfunction as the mechanism of segregation distortion in Drosophila melanogaster. Genetics 58:2240-2245.

Hettyey, A., and J. D. Roberts. 2006. Sperm traits of the quacking frog, Crinia georgiana: intra- and interpopulation variation in a species with a high risk of sperm competition. Behavioral Ecology and Sociobiology 59:389-396.

Hingle, A., K. Fowler, and A. Pomiankowski. 2001. The effect of transient food stress on female mate preference in the stalk-eyed fly Cyrtodiopsis dalmanni. Proceedings of the Roval Society B 268:1239-1244.

Holman, L., T. A. R. Price, N. Wedell, and H. Kokko. 2015. Coevolutionary dynamics of polyandry and sex-linked meiotic drive. Evolution 69:709-720.

Hosken, D. J., and P. I. Ward. 2001. Experimental evidence for testis size evolution via sperm competition. Ecology Letters 4:10-13.

Hurst, G. D. D., and J. H. Werren. 2001. The role of selfish genetic elements in eukaryotic evolution. Nature Reviews Genetics 2:597-606.

Hurst, L. D., and A. Pomiankowski. 1991. Causes of sex ratio bias may account for unisexual sterility in hybrids: a new explanation of Haldane's rule and related phenomena. Genetics 128:841-858.

Jaenike, J. 1996. Sex-ratio meiotic drive in the Drosophila quinaria group. American Naturalist 148:237-254.

2001. Sex chromosome meiotic drive. Annual Review of Ecology and Systematics 32:25-49.

Johns, P. M., L. L. Wolfenbarger, and G. S. Wilkinson. 2005. Genetic linkage between a sexually selected trait and $\mathrm{X}$ chromosome meiotic drive. Proceedings of the Roval Societv B 272:2097-2103.

Kirkpatrick, M. 2010. How and why chromosome inversions evolve. PLoS Biology 8:e1000501

Larracuente, A. M., and D. C. Presgraves. 2012. The selfish Segregation Distorter gene complex of Drosophila melanogaster. Genetics 192:33-53. 
Lindholm, A. K., K. A. Dyer, R. C. Firman, L. Fishman, W. Forstmeier, L. Holman, H. Johannesson, et al. 2016. The ecology and evolutionary dynamics of meiotic drive. Trends in Ecology and Evolution 31:315-326.

Lindholm, A. K., K. Musolf, A. Weidt, and B. König. 2013. Mate choice for genetic compatibility in the house mouse. Ecology and Evolution 3:1231-1247.

Lindholm, A. K., and T. A. R. Price. 2016. The evolutionary consequences of selfish genetic elements. Current Zoology 62:655-658.

Manser, A., A. K. Lindholm, L. W. Simmons, and R. C. Firman. 2017. Sperm competition suppresses gene drive among experimentally evolving populations of house mice. Molecular Ecology 26:5784-5792.

Meade, L. C., D. Dinneen, R. Kad, D. M. Lynch, K. Fowler, and A. Pomiankowski. 2018. Ejaculate sperm number compensation in stalk-eyed flies carrying a selfish meiotic drive element. 122:916-926.

Meade, L. C., S. R. Finnegan, R. Kad, K. Fowler, and A. Pomiankowski. 2020. Data from: Maintenance of fertility in the face of meiotic drive. American Naturalist, Dryad Digital Repository, https://doi.org/10.5061/dryad.088kq34.

Paczolt, K. A., J. A. Reinhardt, and G. S. Wilkinson. 2017. Contrasting patterns of X-chromosome divergence underlie multiple sex-ratio polymorphisms in stalk-eyed flies. Journal of Evolutionary Biology 30:1772-1784.

Palopoli, M. F., and C. I. Wu. 1996. Rapid evolution of a coadapted gene complex: evidence from the Segregation Distorter (SD) system of meiotic drive in Drosophila melanogaster. Genetics 143:1675-1688.

Panhuis, T. M., and G. S. Wilkinson. 1999. Exaggerated male eye span influences contest outcome in stalk-eyed flies (Diopsidae). Behavioral Ecology and Sociobiology 46:221-227.

Pinzone, C. A., and K. A. Dyer. 2013. Association of polyandry and sex-ratio drive prevalence in natural populations of Drosophila neotestacea. Proceedings of the Royal Society B 280:20131397.

Pitnick, S., G. T. Miller, J. Reagan, and B. Holland. 2001. Males' evolutionary responses to experimental removal of sexual selection. Proceedings of the Royal Society B 268:1071-1080.

Presgraves, D. C., E. Severance, and G. S. Wilkinson. 1997. Sex chromosome meiotic drive in stalk-eyed flies. Genetics 147:11691180.

Price, T. A. R., A. J. Bretman, T. D. Avent, R. R. Snook, G. D. D. Hurst, and N. Wedell. 2008a. Sex ratio distorter reduces sperm competitive ability in an insect. Evolution 62:1644-1652.

Price, T. A. R., A. J. Bretman, A. C. Gradilla, J. Reger, M. L. Taylor, P. Giraldo-Perez, A. Campbell, et al. 2014. Does polyandry control population sex ratio via regulation of a selfish gene? Proceedings of the Roval Society B 281:20133259.

Price, T. A. R., D. J. Hodgson, Z. Lewis, G. D. D. Hurst, and N. Wedell. 2008b. Selfish genetic elements promote polyandry in a fly. Science 322:1241-1243.

Price, T. A. R., R. C. Hoskyns, H. Rapley, J. C. Evans, and N. Wedell. 2012. No evidence that temperature-related fertility differences influence the distribution of a selfish genetic element. Functional Ecology 26:657-665.

Price, T. A. R., and N. Wedell. 2008. Selfish genetic elements and sexual selection: their impact on male fertility. Genetica 134:99111.

Reinhardt, J. A., C. L. Brand, K. A. Paczolt, P. M. Johns, R. H. Baker, and G. S. Wilkinson. 2014. Meiotic drive impacts expres- sion and evolution of X-linked genes in stalk-eyed flies. PLoS Genetics 10:e1004362.

Reinhold, K., L. Engqvist, B. Misof, and J. Kurtz. 1999. Meiotic drive and evolution of female choice. Proceedings of the Roval Society B 266:1341-1345.

Rogers, D. W., R. H. Baker, T. Chapman, M. Denniff, A. Pomiankowski, and K. Fowler. 2005a. Direct and correlated responses to artificial selection on male mating frequency in the stalk-eyed fly Cyrtodiopsis dalmanni. Journal of Evolutionary Biology 18:642-650.

Rogers, D. W., T. Chapman, K. Fowler, and A. Pomiankowski. $2005 b$. Mating-induced reduction in accessory reproductive organ size in the stalk-eyed fly Cyrtodiopsis dalmanni. BMC Evolutionary Biology 5:37.

Rogers, D. W., M. Denniff, T. Chapman, K. Fowler, and A. Pomiankowski. 2008. Male sexual ornament size is positively associated with reproductive morphology and enhanced fertility in the stalk-eyed fly Teleopsis dalmanni. BMC Evolutionary Biology $8: 236$.

Rydzewski, W. T., S. A. Carioscia, G. Liévano, V. D. Lynch, and M. M. Patten. 2016. Sexual antagonism and meiotic drive cause stable linkage disequilibrium and favour reduced recombination on the X chromosome. Journal of Evolutionary Biology 29:12471256.

Silver, L. M. 1985. Mouse $t$ haplotypes. Annual Review of Genetics 19:179-208.

Simmons, L. W., and F. García-González. 2008. Evolutionary reduction in testes size and competitive fertilization success in response to the experimental removal of sexual selection in dung beetles. Evolution 62:2580-2591.

Small, J., S. Cotton, K. Fowler, and A. Pomiankowski. 2009. Male eyespan and resource ownership affect contest outcome in the stalk-eyed fly, Teleopsis dalmanni. Animal Behaviour 78:12131220 .

Swallow, J. G., L. E. Wallace, S. J. Christianson, P. M. Johns, and G. S. Wilkinson. 2005. Genetic divergence does not predict change in ornament expression among populations of stalk-eyed flies. Molecular Ecology 14:3787-3800.

Tao, Y., J. P. Masly, L. Araripe, Y. Ke, and D. L. Hartl. 2007. A sexratio meiotic drive system in Drosophila simulans. I. An autosomal suppressor. PLoS Biology 5:e292.

Taylor, D. R., and P. K. Ingvarsson. 2003. Common features of segregation distortion in plants and animals. Genetica 117:2735.

Taylor, D. R., M. J. Saur, and E. Adams. 1999. Pollen performance and sex-ratio evolution in a dioecious plant. Evolution 53:10281036.

Taylor, J. E., and J. Jaenike. 2002. Sperm competition and the dynamics of X chromosome drive: stability and extinction. Genetics 160:1721-1731.

Wedell, N. 2013. The dynamic relationship between polyandry and selfish genetic elements. Philosophical Transactions of the Roval Society B 368:20120049.

Werren, J. H. 2011. Selfish genetic elements, genetic conflict, and evolutionary innovation. Proceedings of the National Academy of Sciences of the USA 108:10863-10870.

Wilkinson, G. S., P. M. Johns, E. S. Kelleher, M. L. Muscedere, and A. Lorsong. 2006. Fitness effects of X chromosome drive in the stalk-eyed fly, Cyrtodiopsis dalmanni. Journal of Evolutionary Biology 19:1851-1860. 
Wilkinson, G. S., H. Kahler, and R. H. Baker. 1998a. Evolution of female mating preferences in stalk-eyed flies. Behavioral Ecology 9:525-533.

Wilkinson, G. S., D. C. Presgraves, and L. Crymes. 1998b. Male eye span in stalk-eyed flies indicates genetic quality by meiotic drive suppression. Nature 391:276-279.

Wilkinson, G. S., and P. R. Reillo. 1994. Female choice response to artificial selection on an exaggerated male trait in a stalk-eyed fly. Proceedings of the Roval Society B 255:1-6.

Wilkinson, G. S., and M. I. Sanchez. 2001. Sperm development, age and sex chromosome meiotic drive in the stalk-eyed fly, Cyrtodiopsis whitei. Heredity 87:17-24.

Wilkinson, G. S., J. G. Swallow, S. J. Christianson, and K. Madden. 2003. Phylogeography of sex ratio and multiple mating in stalkeyed flies from Southeast Asia. Genetica 117:37-46.

Wolfenbarger, L. L., and G. S. Wilkinson. 2001. Sex-linked expression of a sexually selected trait in the stalk-eyed fly, Cyrtodiopsis dalmanni. Evolution 55:103-110.

Zeh, J. A., and D. W. Zeh. 1997. The evolution of polyandry. II. Postcopulatory defenses against genetic incompatibility. Proceedings of the Royal Society B 264:69-75.

\section{References Cited Only in the Online Enhancements}

Bruford, M. W., O. Hanotte, J. F. Y. Brookfield, and T. Burke. 1998. Multi and single locus DNA fingerprinting. Pages 287-336 in A. R. Hoelzel, ed. Molecular analysis of populations: a practical approach. 2nd ed. IRL, Oxford.

Covarrubias-Pazaran, G., L. Diaz-Garcia, B. Schlautman, W. Salazar, and J. Zalapa. 2016. Fragman: an R package for fragment analysis. BMC Genetics 17:62. https://doi.org/10.1186/s12863-016-0365-6.

Fox, J., and S. Weisberg. 2011. An R companion to applied regression. 2nd ed. Sage, Thousand Oaks, CA.

R Core Team. 2016. R: a language and environment for statistical computing. R Foundation for Statistical Computing, Vienna.

Rogers, D. W., C. A. Grant, T. Chapman, A. Pomiankowski, and K. Fowler. 2006. The influence of male and female eyespan on fertility in the stalk-eyed fly, Cyrtodiopsis dalmanni. Animal Behaviour 72:1363-1369. https://doi.org/10.1016/j.anbehav.2006.03 .027 . Editor: Alice A. Winn

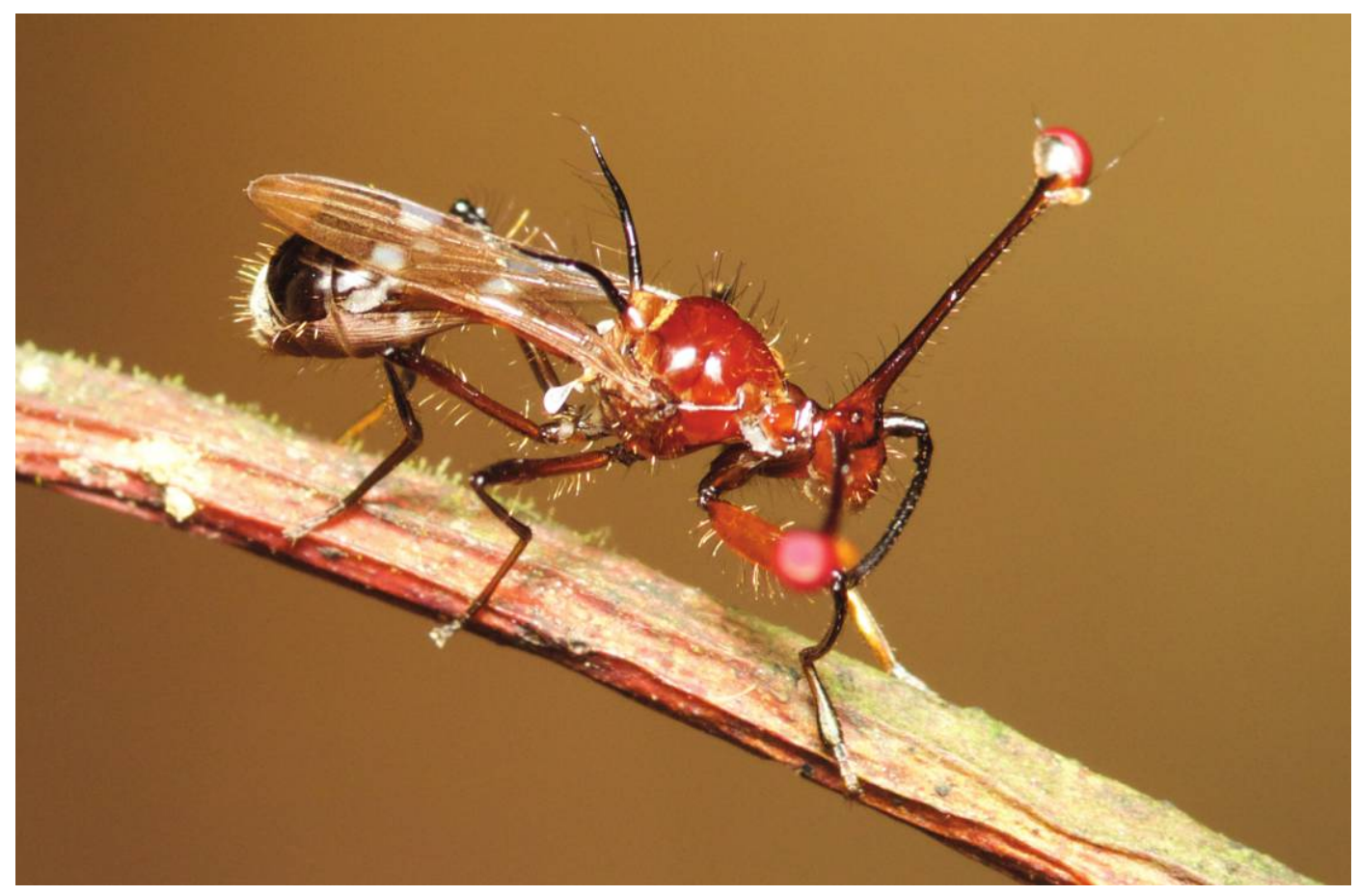

A male Teleopsis dalmanni stalk-eyed fly. Photo credit: Kiran Lee, University College London. 